\title{
The Emergence of the Book
}

\section{Glenn A. Anderson}

\begin{abstract}
Archaeological discoveries during the past century provide documentary evidence for the ratio of rolls to codices during the first four centuries of our era. This ratio differs markedly from Christian to Jewish and pagan writings, suggesting that our book form may initially have been a Christian strategy to distinguish Christian from other writings and that this format, when its physical advantages became evident, was then adopted by the larger culture. Using this evidence, C. H. Roberts has suggested two historical reconstructions of the first use of the codex form.
\end{abstract}

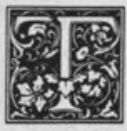

he role of utility in cultural change is often assumed to be primary: why else would a new technology be adopted but for its increased utility? Scholarship based on this assumption tends to confine the decisions that precede change within the boundaries of utility. Such efforts are supported by, and probably reflect, frequent attempts by scholars to locate the stimulus for historical initiative in economic or social necessity.

This article presents a review of an important but obscure historical event-the adoption of the codex or book form. The victory of the codex over the once prestigious roll has been widely regarded as a triumph of practicality and economic good sense. Recent archaeological discoveries, however, have provided evidence that supports a different understanding of the origin of what we call the book, an understanding that does not banish utility completely as a factor but stresses the role of other factors in this fundamental change.

This account of the emergence of our book form also provides a condensed historical review for librarians and scholars who may overestimate the obscurity of the issues surrounding the adoption of the codex form and regard them as specialist's turf. In comparison to the change to the codex form, the study of the complemen- tary developments of paper and printing and their momentous effects on the history of the book have fed a literature that has spilled over into the popular level.

Few librarians or scholars are puzzled by references to Gutenberg or moveable type. One may infer, therefore, that this aspect of Western history is part of our general knowledge. Similarly, contemporary usage of computer technology for information storage and retrieval has also been the subject of an expanding literature-much of it at the popular level. This literature can claim a kind of squatter's rights in the consciousness of even the most bookish scholar. The equally momentous replacement of the roll by the codex form, however, has only the most marginal place in the general knowledge of those who work with books. Perhaps this is as it should be for a development that is almost two thousand years old and obscured by highly technical descriptions and vague, fragmented data. Nonetheless, the centrality of the book form within Western civilization lends a natural interest to speculations about its origins.

The adoption of the codex form exhibited the following pattern:

"The codex owed its existence to the substitution of vellum [parchment] for papyrus as the common writing material for Greek and Latin 
literature; vellum was a tough material capable of being inscribed on both sides, and the leaves could be stitched and bound in a form similar to books of modern times."

Two elements in this description deserve attention:

1. the inference that the change in writing material from papyrus to parchment led to the change from roll to codex form, and

2. the assumption that the physical shortcomings of the roll led to the overthrow of papyrus as the scribes' chosen material (see figure 1).

To claim that the change from papyrus to parchment caused, or was the same as, the change from the roll to the codex form is a misunderstanding. Such a claim does not take into account the substantial evidence provided by extant manuscripts from the first four centuries of our era: these manuscripts are prizes from the stream of archaeological discoveries made in the last one hundred years. Since 1897, large manuscript collections have been discovered at Oxyrhynchus (south of Cairo in Egypt), Antinoë (only one hundred miles from Oxyrhynchus), north of
Luxor (also in Egypt), and along the west shore of the Dead Sea. Although the Dead Sea Scrolls and Nag Hammadi codices are more famous, the immense papyrus collection discovered at Oxyrhynchus between 1887 and 1928 is important for its fragments of classical literature, gospels, apocrypha, patristic texts, and commercial and civil items.

The classification and listing of the various manuscripts has left a concrete record of early forms of writing. While these extant records offer only a tiny sampling of ancient writings, similarities between discoveries suggest that these samples are representative. Extant documents indicate that papyrus and parchment were used interchangeably in rolls and codices. Because parchment rolls and papyrus books remained in use for centuries after the adoption of the codex form, there is no reason to attribute that adoption to the material used in the roll or codex. ${ }^{2}$

The second portion of the explanation quoted above implies that parchment has a toughness, durability, and versatility, because both sides can be written on. This made papyrus second rate. In fact, extant papyruses are sometimes inscribed on
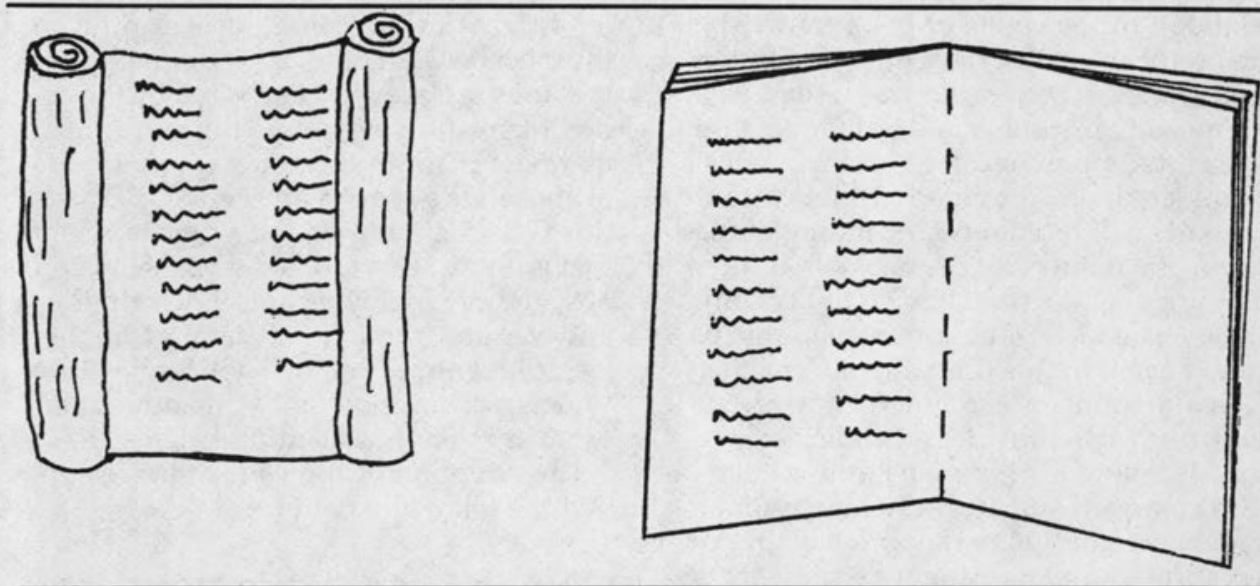

Similarities between the early codex and the roll are considerable. The same narrow columns of text were used in the codex-as many as four columns appeared on a single page.

\section{FIGURE 1}


both sides, as the existence of a technical term-opisthograph-for a roll written on both sides indicates. The popular vision of papyrus as a thin, fragile material, dried to brittleness, is a misconception. Papyrus is sturdy, durable, and flexible. ${ }^{3}$

The existence of storage facilities for rolls in papyrus libraries and the use of papyrus for many forms of writing long after parchment was widely available illustrate that papyrus was regarded as satisfactory for archival purposes. Other factors, e.g., ease of use, ease in marking one's place, safety of storage, and cost, have also been cited as reasons for adopting the codex. However, they describe advantages that are imaginary, inaccurate, or inadequately demonstrated. Another factor, the prestige of the roll, is impossible to weigh. Yet the formidable power of prestige and habit that the roll enjoyed among scribes ensured for the codex a long-time status as poor cousin. The extant documents present a pattern in which the roll was used for most writings while the codex was only occasionally used.

The Greek literary manuscripts that have survived from the first four centuries of our era provide a chart of the number of rolls produced as compared to codices. Assuming that these manuscripts represent the usual proportion between rolls and codices, the following pattern of use emerges:

- in the first century, less than one per-
'... among Greek literary manuscripts, the codex form gained a dominant position between the fourth and fifth centuries, almost three hundred years after the first use of the codex form."

cent of the extant manuscripts are codices,

- in the second century, only two percent of the extant manuscripts are codices,

- in the third century, seventeen percent are codices, and

- by the beginning of the fifth century, ninety percent of the extant manuscripts are codices. ${ }^{4}$

This pattern indicates that among Greek literary manuscripts, the codex form gained a dominant position between the fourth and fifth centuries, almost three hundred years after the first use of the codex form (see table 1).

Christian biblical manuscripts from the first four centuries present a remarkably different pattern from that of the Greek literary manuscripts. Among 172 extant papyrus and parchment Christian biblical texts written before A.D. 400, 158 are codices and only 14 are rolls. ${ }^{5}$ Of the 14 rolls, several have a biblical text written on the other side of an already used roll so that

TABLE 1

ROLLS AND CODICES AMONG GREEK LITERARY MANUSCRIPTS

\begin{tabular}{cccc}
\hline \hline Century & Rolls & Codices & Percentage of Codices \\
\hline 1 & 353 & 3 & Less than \% $^{*}$ \\
2 & $(252)$ & $(1)$ & $2 \%$ \\
3 & 1132 & 24 & $17 \%$ \\
& $(857)$ & $(4)$ & $70 \%$ \\
4 & 607 & 126 & $90 \%$ \\
\hline & $(406)$ & $(93)$ & $90 \%$ \\
(beginning of century) & 66 & $(99)$ & 122 \\
\hline
\end{tabular}

\footnotetext{
* To nearest $1 / 2 \%$.
}

Note: These data are presented using a statistical method offered by William A. Willis in "A Census of the Literary Papyri from Egypt," Greek, Roman, and Byzantine Studies, 9:205-41 (1968). Willis divides manuscripts that have been suggested as spanning two centuries equally between the centuries in question. Parenthetical figures indicate manuscripts that have been firmly dated. 
the roll format seems determined by the available material. ${ }^{6}$ Several others are probably of Jewish origin, and only one roll, a text of Isaiah, has a Christian biblical text on a roll when the codex form could presumably have been used as easily. Taken as a body, Christian biblical writings before the year 400 are almost invariably in codex form. This represents a marked contrast to the high percentage of Greek literary manuscripts on rolls during the same time.

A similar study of the earliest stratum of Christian biblical writings emphasizes this pronounced difference from Greek literary writings. Of the 172 Christian biblical manuscripts from the first four centuries, 11 can be assigned to the second century. Compared with Greek literary manuscripts, only one and one-half percent of which were in codex form during the second century, all of the earliest existing Christian biblical texts are in codex form. All are also on papyrus. Despite vagaries in dating documents of such age and the uncertainty of definition for key terms, e.g., biblical, the earliest versions of the Christian Bible are always in codex form. That each of these codex manuscripts was discovered in Egypt, where the place of

\section{Greek Literary Manuscripts}

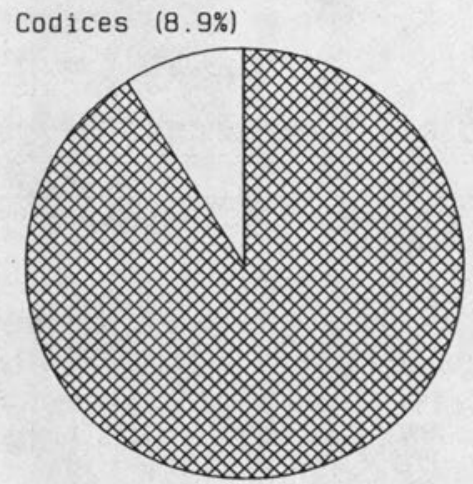

Rolls (91.1\%)

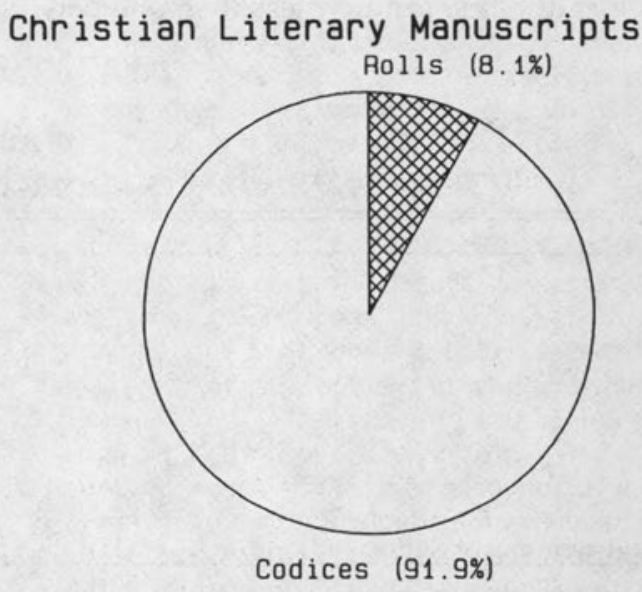

FIGURE 2

First through Fourth Century 


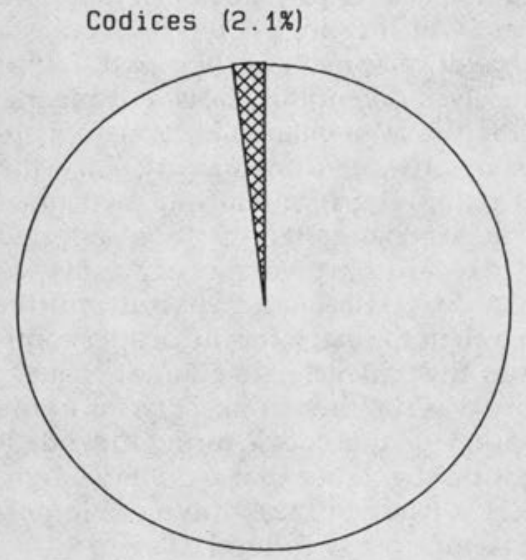

Rolls (97.9\%)

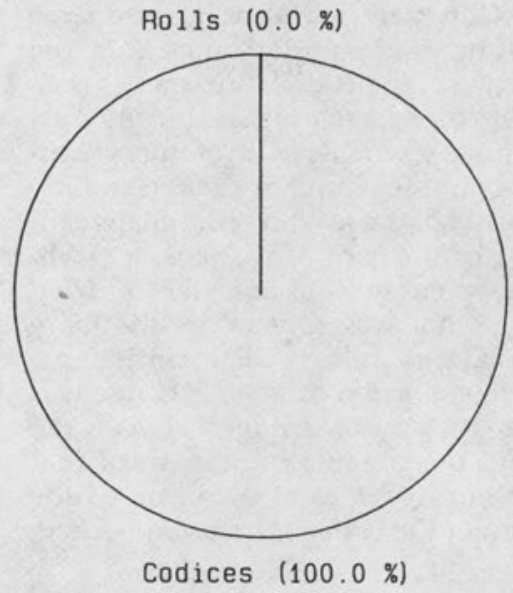

Codices (100.0\%)

FIGURE 3

Second Century

evangelist Mark, using one of the parchment notebooks common in Rome for legal or official business, wrote the events that the Apostle Peter had recounted to him. According to this thesis, Mark's Gospel, the first to appear in written form, was later recopied in Alexandria, associated with Mark by an ancient tradition, on papyrus. This format then acquired the weight of a precedent as well as symbolic value as a manifestation of Christianity's break with the roll, which had a close association with Jewish law and with pagan literature. ${ }^{8}$ First-century Alexandria's place in Christianity is, however, clouded by an almost total lack of evidence, and because the likelihood that either Alexandrian practice or Mark's Gospel, which is very infrequently cited in early Christian literature, carried such weight in primitive Christianity is problematic, Roberts later revised this hypothesis.

The adoption of the codex by Christians probably occurred, not in Rome, but in Jerusalem or Antioch, where Greek manuscripts were needed for the Gentile mission. The large Jewish community, either in Jerusalem or Antioch, used waxed tablets and papyrus tablets. To record the oral law passed on by Jesus, a large school of scribes and scholars developed. The scribes occupied by these tasks developed the first codex no later than A.D. 100.' In the case of both theses, the codex form was adopted primarily to differentiate its Christian users from both Jewish and pagan writers.

While Roberts' theses cannot be proved, he presents differing speculations that help to explain much of the available documentary evidence. Part of the attractiveness of these historical reconstructions is their specificity-and this in a subject where questions, gaps, and caution are far

\footnotetext{
"Like the new publishing forms in our own time, any major change tempts those affected by it to regard it in revolutionary terms - to stress differences and discontinuities rather than to search for the deeper continuities that characterize cultural change."
} 
more common than concrete assertion. If, as Roberts suggests, the adoption of the book form was intimately bound to the rise of Christianity and occurred in the first century, our understanding of the emergence of the codex form merits revision. Of considerable interest in its own right, this revised view also admits speculation about the nature of change and the psychology of those who bring change. In the case of the early Christians, a group that was in many ways inflexible initiated a change that was resisted by the more flexible Greek culture. The Christians, possessing a vision in which change was seen as a necessary bridge between the past and the organic fulfillment of that past, seem never to have regarded the adoption of the codex form as an issue in itself. Rather, the codex played a small part in a larger vision. The supporters of the roll, lacking any larger perspective against which change could be seen as a natural development of their past, found themselves defending stasis and regarding the threat of change in terms of rupture, divorce, or discontinuity. Like the new publishing forms in our own time, any major change tempts those affected by it to regard it in revolutionary terms-to stress differences and discontinuities rather than to search for the deeper continuities that characterize cultural change. Utility was not the strongest factor in the adoption of the codex form. Indeed, it might be suggested that a utilitarian emphasis is likely to mask the more important factors in any cultural change.

\section{REFERENCES AND NOTES}

1. Bookman's Glossary, 6th ed., ed. Jean Peters (New York: Bowker, 1983), p.53-54.

2. E. G. Turner, in Greek Papyri (Oxford: Clarendon, 1968), p.42-53, devotes a chapter to the geographical distribution of archaeological finds. Roger A. Pack, Greek and Latin Literary Texts from Greco-Roman Egypt, 2d. ed. (Ann Arbor, Mich.: Univ. of Michigan Pr., 1965), indicates a proportion of rolls to codices similar to that found in the first edition of his work (Ann Arbor, Mich.: Univ. of Michigan Pr., 1952). Similarly, Colin H. Roberts, in "The Codex," Proceedings of the British Academy, 40 (1954), reports statistics similar to those of Pack and to those of the later Roberts and T.C. Skeat, Birth of the Codex (London: Oxford Univ. Pr., 1983).

3. Naphtali Lewis, Papyrus in Classical Antiquity (London: Oxford Univ. Pr., 1974), p.60-61.

4. For other than Christian texts, data are supplied by Roger A. Pack, Greek and Latin Literary Texts from Greco-Roman Egypt, 2 d ed.; brought up to 1970 by F. Eubel, "Literarische Texte unter Ausschluss der Christlichen," Archiv für Papyrusforschung, 21:170-82 (1971). For codices, data from E. G. Turner, The Typology of the Early Codex (Philadelphia: Univ. bf Pennsylvania Pr., 1977) are very helpful. Roberts and Skeat, Birth of the Codex, p.37, evaluate and accept the data provided by Pack, Eubel, and Turner.

5. The data for Christian papyruses are presented by Kurt Aland, Repertorium der Grieschischen Christlichen Papyri (New York: DeGruyter, 1976) and Joseph van Haelst, Catalogue des Papyrus Littéraires Juifs et Crétians (Paris: Publications of the Sorbonne, 1976); supplemented by Kurt Treu, "Christliche Papyri," Archiv für Papyrusforschung, 26;149-59 (1978) and 27:251-58 (1980). Roberts and Skeat, Birth of the Codex, present the data provided by Aland, van Haelst, and Treu.

6. The catalog numbers of these fourteen rolls in van Haelst (Catalogue des Papyrus Littéraires Juifs et Crétians) are 14, 44 and 559, 48, 104, 109, 133, 148, 167, 174, 286, 300, 319, 459, and 537.

7. This is the conclusion of Roberts and Skeat, Birth of the Codex, p.40-41. There is substantial agreement among scholars about several of these items (and unanimity about five of them). Some scholars would include other items on the list; others would exclude items from it. Ten of the eleven codices listed by Roberts and Skeat are listed by Turner, Typology of the Early Codex, and in van Haelst, Catalogue des Papyrus Littéraires Juifs et Crétians. Complete agreement among scholars does not exist in this matter.

8. Colin H. Roberts, "The Codex," Proceedings of the British Academy, 40:169-204 (1954).

9. Roberts and Skeat, The Birth of the Codex, p.54-61. 